\title{
Why World Vision supports healthy timing and spacing of pregnancies to improve maternal and child health: a faith- based perspective
}

\author{
Adrienne A. Allison a and Eloho E. Basikoro ${ }^{b}$ \\ a MA, MPA, Senior Technical Adviser, World Vision, USA \\ ${ }^{\mathrm{b}} \mathrm{PhD}$, World Vision, USA
}

\section{Abstract}

World Vision, a Christian humanitarian organization, began large family planning programs in 2007, with support from the United States Agency for International Development (USAID). As new data were published in 2008 and again in 2014, measuring the impact of the length of the preceding birth-to-conception interval on maternal, infant, and child mortality and child stunting, World Vision adopted the term "healthy timing and spacing of pregnancies" (HTSP) as its approach to family planning. This term refocused family planning efforts to emphasize the health benefits for mothers and children, and was quickly accepted by faith leaders. The data are explained, and the consequences of shorter and longer birth intervals outlined.

\section{Background}

In 2008, the ICF Macro team analyzed data from 52 Demographic Health Surveys (DHSs) conducted from 2000 to 2005 on the relationship between the duration of birth-to-conception interval, and maternal and child mortality and nutritional status for 1.12 million births. ${ }^{1}$ The analyses clearly showed that a longer birth-to-conception interval resulted in the lowest levels of maternal, infant, and child mortality. The data also showed a clear and compelling relationship between the length of the pregnancy-to-conception interval and stunting. As the interval lengthened, stunting steadily declined. ${ }^{1}$ (In addition to being too short for their age, stunted children experience cognitive delays and other irreversible physical and mental impairments.)

A follow-on DHS study included two additional variables: birth order and age of mother. Data from 45 DHSs, conducted between 2006 and 2012 included 340,000 living children under the age of 5. ${ }^{2}$ The data affirmed earlier findings.
Impact on mortality:

- Birth-to-conception intervals of less than 18 months has an increased risk of neonatal mortality.

- Children conceived within 6 months of the preceding birth are 2.2 times more likely to die before age five, compared to those conceived 36 to 47 months after the previous birth.

Impact on stunting:

- Birth-to-conception intervals of less than 1,000 days increases the prevalence of stunting.

- Children conceived after an interval of 12 to 17 months are 23 percent more likely to be stunted than those conceived after an interval of 36 to 47 months.

Impact of age of mother on stunting and child mortality:

- Children of mothers less than 18 years have a greater risk of being stunted and underweight. 
These children also face a greater risk of dying before their fifth birthday.

- Children of mothers more than 34 years old have a greater risk of dying during infancy. However, children born to older mothers are less likely to be stunted and underweight than those born to mothers less than 18 years of age. ${ }^{2}$

In 2012, The Lancet published a report on birth timing and spacing that verified this research, and supported the integration of family planning with maternal and child health programs. The main findings were:

- The risk of prematurity and low birth weight doubled when conception occurred within 6 months of the previous birth, compared to those conceived 36 to 47 months after the previous birth.

- Children born to girls younger than 18 years had an excess mortality risk rate of about 40 percent compared to women 20 to 24 years of age.

- Meeting the need for contraception would have reduced maternal deaths by 30 percent. $^{3}$

World Vision (WV), a Christian humanitarian organization dedicated to working with children, their families, and their communities worldwide, supports the implementation of voluntary family planning programs based on the best medical knowledge and good medical ethics. WV does not recommend, provide, or support abortion. The organization respects the rights of women and men to make their own decisions about family size and pregnancy spacing. The World Vision Partnership has confirmed that HTSP directly supports the organizational goal to "sustain the well-being of children, families, and communities."

Based on the data cited above, WV refocused family planning to emphasize the health benefits of timing and spacing pregnancies to save lives. WV replaced "family planning" with "HTSP," and integrated HTSP counseling and services within maternal and child health programs generally implemented by ministries of health. To make messages about timing and spacing more easily understood and remem- bered, WV created posters and counseling materials to encourage women and men to avoid pregnancies when a mother was "too young or too old" or has pregnancies that were "too many, too soon."

\section{What is Healthy Timing and Spacing of Pregnancies (HTSP)?}

HTSP promotes informed decision-making about delaying, spacing, or limiting pregnancies to achieve the optimal results for women, newborns, infants, and children. HTSP emphasizes healthy pregnancy. Hence, its messages have been especially appealing to faith-based organizations (FBOs) and faith leaders. ${ }^{4}$

HTSP includes four key messages:

1. Delay the first pregnancy until a girl is at least 18 years old.

Pregnancy and childbirth are the leading causes of death in girls aged 15-19 globally. ${ }^{5}$ Girls of this age are twice as likely to die in childbirth compared to women aged 20-24, and their infants are up to 10 times more likely to die before their second birthdays. In sub-Saharan Africa, more that 50 percent of first births are to adolescent girls. ${ }^{5}$

2. Wait until a child is at least 2 years old before trying for another child.

Infants thrive when they have a full two years of breast-feeding. Well-nourished children are less likely to be vulnerable to illnesses that result in poor mental and physical growth. If the next child is conceived while the older child is still breast-feeding, breast-feeding may falter and the child may be weaned too soon. It is the older child who is more likely to die. ${ }^{5}$

3. Wait at least 6 months after miscarriage before trying for another child.

Infants conceived less than 6 months from the previous pregnancy are more likely to be premature, be small for gestational age, have low birth weight, or be stillborn. Mothers are also more likely to die. ${ }^{5}$ 
4. Limit pregnancies to a mother's healthiest years-ages 18-34.

The risk of a mother dying in childbirth increases sharply when she is more than 34 years old, or when she has more than four children. ${ }^{5}$

\section{Family planning and HTSP}

Family planning programs were introduced in the 1960 s to slow population growth rates in developing countries that did not have resources to meet the needs of their rapidly growing populations. The demographic rationale became the dominant rationale in family planning. ${ }^{6}$ More recently, the concept of a "demographic dividend" has been studied and supported in several countries. This theory links economic growth to the population age structure, finding that countries with higher numbers of working adults and fewer dependent children have a stronger, more sustained economic growth compared to countries with fewer skilled laborers and higher dependency ratios. A larger working class population stimulates job growth, economic productivity, and higher incomes, which will in turn, lead to increased savings and investment. ${ }^{7,8}$

The demographic and economic rationales for family planning resonate with governments but not with people. For example, Senegal adopted a population policy in the 1960s that supported contraceptive use $\mathrm{e}^{\mathrm{i}}$

i Contraceptive methods include hormonal contraception (pills, injectables, and implants), intrauterine devices (IUDs), barrier methods (male and female condoms, spermicides), emergency contraceptive pills (ECPs), fertility awareness methods (FAMs), withdrawal, and sterilization. Many faith leaders show a preference for natural FAMs of family planning, such as the Standard Days Method (SDM) and lactational amenorrhea method (LAM), and withdrawal. These methods have no side effects and do not require medical procedures, devices, or hormones.

SDM helps couples to avoid pregnancies at the times when the woman is most fertile by tracking her menstrual cycle, and requires a couple to avoid sex or use a barrier method during this time. LAM protects women from conception for the first six months after birth. Once the mother introduces complimentary feeding, she no longer is amenorrhoeic and needs an alternative method of contraception. Withdrawal involves a man withdrawing his penis during to reduce family size. ${ }^{9}$ Yet, 50 years later, the contraceptive prevalence rate was just 11 percent. Their policy that focused on limiting population yielded little impact.

Within the developing world in general, "family planning" is often associated with government efforts to limit family size, which can be viewed as a form of intrusion into the customary cultural context. ${ }^{6}$ Political, religious, and cultural barriers reduced contraceptive use. HTSP messages, with their new focus on improving health and saving lives to benefit the well-being of families and communities, are more acceptable to faith leaders. Religious beliefs and principles are powerful influences on individual behaviors and community actions, including health-related practices. In sub-Saharan Africa, a 2006 survey found that people trust faithbased organizations more than they trust their own national governments. ${ }^{10}$ As such, FBOs and religious leaders have an immense opportunity to educate communities about the healthy timing and spacing of pregnancies, and methods of family planning.

Mobilizing faith leaders to provide information on HTSP and contraception within the values and belief systems of their communities is emerging as a productive approach to building support for HTSP. This could help reduce maternal mortality by 35 percent, cut abortion in developing countries by 70 percent, and lower the infant mortality rate by 10 to 20 percent. ${ }^{11}$

The health rationale of HTSP surmounts religious barriers. Faith leaders often determine and dictate which sexual and reproductive health behaviors are prescribed or prohibited. WV creates a safe space for them to discuss religious teachings, and learn, share, and debate their perceptions and understanding of HTSP and contraception. This process often transforms their own understanding and changes their practices. As they adopt new behaviors, they and their families become models for HTSP within their faith communities.

sex and ejaculating outside of the vagina to prevent sperm from entering the woman's body. 
WV, with support from USAID, implemented HTSP programs in Haiti, India, and Senegal. In Uttar Pradesh, India, community health workers worked with local faith leaders to build their support and advocacy for HTSP. Within 14 months, there were 67,989 new contraceptive users with an estimated contraceptive prevalence rate (CPR) of 77 percent in targeted communities. (CPR $=$ Number of women of reproductive age (WRA) using contraception / total number of WRA x 100).

Religious leaders played an essential role in building support for HTSP in Fatick District, Senegal. When the imams learned that timing and spacing births would lower mortality rates and improve the wellbeing of their communities, they became strong advocates for family planning, particularly as the Koran encouraged mothers to breastfeed their children for a full two years. The Catholic sisters, who supported three health posts, counseled clients on the Lactational Amenorrhea Method and the Standard Days Method, and referred them to $\mathrm{MOH}$ health posts for other methods. The CPR at these health posts increased from 12 to 17 percent in one year.

\section{Implication for policy and practice}

1. By focusing on the health benefits of using contraception to time and space pregnancies, faith leaders, civic leaders, mothers, and fathers often change their earlier opinions and adopt better and healthful behaviors, and influence others to do the same.
2. Nutrition programs need to include HTSP counseling and access to contraceptive services, as the ICF Macro analyses show that there is a 50 percent reduction in stunting when the birth-to-conception interval is 36 to 47 months. By leveraging the benefits of HTSP with the right supportive policies and practices, countries can be well on their way to achieving the demographic dividend.

3. Community conversations led by trained providers can introduce villagers to new concepts and a new, stigma-free vocabulary in communications on HTSP. Such communications, especially at the household level, are crucial for influencing and mobilizing communities to change harmful socio-cultural norms and practices around gender, HIV/AIDS, and child protection that undermine maternal and child health.

4. The risk of adolescent girls' mortality is very high, as is the risk of mortality for newborns. Adolescent girls and boys need age-appropriate information, counseling, and services to protect them from unplanned pregnancies. The HTSP approach in family planning helps to expose adolescents to a wide range of family planning friendly services, which protects them from unplanned pregnancies and sexually transmitted diseases. 


\section{Allison and Basikoro}

\section{References}

1 Rutstein S. Further evidence of the effects of preceding birth intervals on neonatal, infant, and under-five-years mortality and nutritional status in developing countries: evidence from the demographic and health surveys [Internet]. DHS Working Paper; 2008. Available from: https://hsprogram.com/pubs/pdf/WP41/WP41.pdf

2 Rutstein S, Winter R. Contraception needed to avoid high-fertility-risk births, and maternal and child deaths that would be averted [Internet]. DHS Analytical Studies; 2015. Available from: https://dhsprogram.com/pubs/pdf/AS50/ AS50.pdf

3 Cleland J, Conde-Agudelo A, Peterson H, Ross J, Tsui, A. Contraception and health. The Lancet. 2012 July 10;380(9837): 149-156. https://doi.org/10.1016/S0140$\underline{6736(12) 60609-6}$

4 United States Agency for International Development [Internet]. HTSP 101: everything you want to know about healthy timing and spacing of pregnancy. [2008]. Available from: http://www.who.int/pmnch/topics/maternal/htsp101. pdf

5 United States Agency for International Development. Reproductive health report [Internet]. 2017. Available from: https://www.k4health.org/search/toolkits/ MCHIP\%2520KPC\%2520survey

\section{Christian Journal for Global Health |}

6 Seltzer JR. The origins and evolution of family planning program in developing countries. California: RAND Publications; 2002

7 Kabeer N. Reversed realities: gender hierarchies in development thought. London: Verso; 1994

8 United States Agency for International Development [Internet]. Healthy timing and spacing of pregnancies: a family planning investment strategy for accelerating the pace of improvements in child survival. [2012]. Available from: https://www.usaid.gov/sites/default/files/documents/1864/calltoaction.pdf

9 Allison A, Foulkes E. Engaging faith leaders in family planning [Internet]. The John Templeton Foundation; 2014. Available from: http://www.ccih.org/WV-Engaging-Faith-Leaders-in-Family-Planning.pdf

10 Tortora B. Africans' confidence in institutions [Internet]. Gallup News Services [2007]. Available from: http:// www.gallup.com/poll/26176/africans-confidence-institutions-which-country-stands-out.aspx

11 Coleman I, Lemmon G. Family planning and U.S. foreign policy [Internet]. Council on Foreign Relations; 2011. Available from: https://www.cfr.org/report/family-planning-and-us-foreign-policy

Peer Reviewed

Competing Interests: None declared.

Correspondence: Adrienne Allison, aallison@worldvision.org; Eloho Basikoro ebasikoro@worldvision.org

Cite this article as: Allison A and Basikoro E. Why World Vision supports healthy timing and spacing of pregnancies to improve maternal and child health: A faith-based perspective. Christian Journal for Global Health. July 2017; 4(2)75-79; https://doi. org/10.15566/cjgh.v4i2.169.

(C) Allison A. and Basikoro E. This is an open-access article distributed under the terms of the Creative Commons Attribution License, which permits unrestricted use, distribution, and reproduction in any medium, provided the original author and source are properly cited. To view a copy of the license, visit http://creativecommons.org/licenses/by/4.0/ 